\title{
Study on Risk and Prevention of Retail Enterprise-Oriented Supply Chain
}

\author{
Huang Xinxiang \\ School of Management, Shanghai University of \\ Engineering Science \\ Shanghai, China \\ paulhxx@126.com
}

\begin{abstract}
With the continuously developing of supply chain mode and management idea, it becomes chief point that how effective cooperation with the supply channels of each enterprise for the most active retail trade of our consumer market. The implementation of supply chain management can solve this problem effectively. But in the operation of the leading retail trade supply chain, the occurrence of some risk factors often lead to the supply chain and enterprises are facing a crisis, recognize these risk factors, and take the necessary measures to against the risk has becoming a major task to our retail trade.
\end{abstract}

Keywords- Retail enterprise; supply chain; risk prevention

\section{INTRODUCTION}

With highlighted of the supply chain management, the international retail supply chain management research has greater progress. Early research mainly is focus on solving retail supply chain operation efficiency issues. Recently, with the development of strategic supply chain system, the research has shifted to the retail supply chain strategic partnership and risk. In our country, the research of retail industry supply chain has just started, which studies always focus on a certain level, not analysis from the suppliers, manufacturers, distributors, retailers, also to the end customers complete chain.

\section{RETAIL ENTERPRISE LEADING SUPPLY CHAIN ANALYSES}

Supply chain is that let a number of interdependent, mutual contact suppliers, manufacturers, distributors, retailers, and until the end user as a whole net structure mode. Study on the key point is the composition of each node of supply chain relationship. Therefore the retail enterprise leading supply chain concept is to make the smallest cost and let the supplier, manufacturer, distributor, retailer, customers effectively combine into a unified body to produce goods, and method of putting the right amount of goods to the right place at the right time. In the all retail supply chain network activities, retailers in a dominant position and making the other members of coordination and control, which show very strong radiation ability and ability of absorbing.

As follows are the management features of retail enterprise oriented supply chain. First of all, the retail enterprise leading supply chain is a strong retail enterprise

\author{
Zhanglei \\ School of Management, Shanghai University of \\ Engineering Science \\ Shanghai, China \\ shtea@163.com
}

as the core. The retailer to maintain normal system operation is the premise of ensuring the normal supply of goods, to ensure that the sales process fluid supply. Retail enterprises have to establish strategic cooperative partnership with the upstream and downstream node enterprises in the design, production, competition strategy, and maintain good coordination. Secondly, for the retail industry, the key lies in the sale of consumer good, while the sales activities lie in procurement. The purchase link, it must be done timely, appropriate, appropriate speed. To do this, in this work the complete process cannot lack distribution management coordination. So for the retail enterprise leading supply chain, procurement management and distribution management important link status is also one of its characteristics. Thirdly, the establishment of shared information platform, Retailers will sell information and inventory information and upstream enterprises to realize the sharing of, so they can be real-time grasp of product sales and market feedback, to maximize the production to keep pace with the market, to improve the retail supply chain market reaction speed, maximum to meet consumer expectations.

\section{RETAIL ENTERPRISE LEADING SUPPLY CHAIN RISK FACTORS}

\section{A. External risk factors}

Supply chain risk caused by many factors, including the factors of natural environment, economic environment, social environment and retail competition. Here we mainly introduce the retail competition risk. Retail industry provide consumers with consuming goods, its activities include the form of stores, convenience stores, supermarkets, large supermarket chains, warehouse club stores, specialty shops, stores and shopping centers. Retail industry in various forms of competition is very severe. For example, the city of similar retail enterprises tends to be similar, operating varieties and management strategies are likely. This leads to various retail enterprises for their own survival and profitability of fierce competition, also leads to its behind the respective supply chain of retail industry will face the competitive pressure from outside. After joining the WTO, foreign retailers with its strong capital strength, good customer service have entered into China. It aggravates our 
country retail competition, and corresponding increase in the retail enterprise leading supply chain operation risk.

B. Retail enterprise dominant within the supply chain

a) Supplier risk

In retail industry, there are long-standing conflicts between suppliers and retailers. In the retail operation of the process, although the retailer can control the display location of commodity, but the supplier is in control of retail supply chain initiative. When the suppliers such as force majeure impact, retail enterprise leading supply chain will be followed by the impact, risk factors will appear. In addition to the retail goods procurement process for supplier selection model is particularly important. When a core enterprise retailer reduces construction cost for short-term interests rather than to avoid the risk of long-term interests. Once a supplier problems, the retail business is a fatal blow.

b) Internal information communication disorder risk

In the supply chain, each node enterprise is independent of the operation and management of economic entities. When the retail supply chain dimensions expands increasingly, become more and more complex in structure, in the process of information transmission of information error chances increase. For example, the information transmission delay will cause between the upstream and downstream enterprises communication is not smooth, then the consumer goods production and customer demand in the respect such as understanding differences arise, can not really grasp the market needs. At the same time, may also produce the bullwhip effect, leading to excessive inventory, increase content to shed cost and idle capital turnover, manage to the enterprise to bring the huge risk. Information risk also easily lead to moral hazard, main show is in between the supplier and the retailer will power reversal. Once the retail enterprises abuse of its power advantage as the core enterprise, other member companies will seek ways to resist, so the results may be made to mutual competition instead of mutual cooperation, then causes the entire retail enterprise leading supply chain profit decline.

c) Inventory risk.

Inventory links relates directly to the enterprise sales operation, to maintain adequate inventory to ensure sales order. Excess stock will occupy the retail enterprise funds, make the enterprise funds chain cannot fast circulation; inventory is too little, cannot satisfy the need of sales may lead to retailers, sales plans to be completed successfully. In addition, the security is an important part of the inventory management, fire, theft, damage or impregnated such problems will also increase the retail enterprise leading supply chain inventory risk.

d) Logistics operation risk

Retail enterprise oriented supply chain management requires retailers to and upstream suppliers to establish long-term stable cooperative partnership; the cooperation is a kind of seamless cooperation. This requires each member company is taken between joint planning, implementation of the unified standard of logistics activities. But in the retail enterprise leading supply chain operation is difficult to achieve this point, which resulted in the product supply, transportation, product, product sales and other cache may occur during articulation errors and logistics technology facilities are not matching problem. These articulation disorders although not significantly, but its occurrence may lead to the supply chain logistics operation is not smooth, so the risk of supply chain.

e) Culture risk in difference enterprise

Retail enterprise in the supply chain are under the different cultural background, different opinions. The differences between the two sides will affect the entire supply chain stability. The enterprises can develop their own cultural characteristics suitable for the formation of the different system. This leads to each node enterprise corporate culture differences is reflected not only in the enterprise business philosophy, culture and system, but also demonstrated in the employee's occupation quality and professionalism, etc. If the parties have not form mutual running-in, so this kind of different corporate culture risks, may make the retail enterprise leading supply chain partnerships to sustain and even collapse.

\section{IV. .PREVENTION STRATEGIES FOR THE SUPPLY CHAIN RISK}

\section{A. Establish the risk early warning and emergency response mechanism}

In the retail enterprise leading supply chain may occur in the various risks, natural risk and social risk as unpredictable risks often supply chain to bring greater impact. To deal with this type of external risks, supply chain managers must improve on the risk of the initiative consciousness; establish a set of risk early warning system and emergency handling system. Before risk happening, try to eliminate all kinds of risks, and forecast the risk of loss degree. In making the warning, time to start contingency system for emergency, emergent natural disasters and social events for emergency treatment, to avoid supply chain to bring serious consequence.

\section{B. Establishment of strategic alliance}

The choice of supply chain partners in supply chain risk management is important one annulus. Retail enterprise dominant within the supply chain faces competition from partner risk factors. These risks as they occur, can lead to the overall supply chain to unravel the serious consequences. Thus, retailers and chain members should make full use of their complementary advantages to play a cooperative competition advantage, also want to consider and partners of cooperation cost and adaptability. On retail enterprise leading supply chain may occur in the profit 
distribution is not equal mutual distrust of the crisis, each member enterprises established close cooperative partnership became strengthen confidence, successful supply chain operation and risk precaution is a prerequisite. Retail enterprise leading supply chain strategic alliance is in enterprise of mutual trust to replace the contradiction between node enterprises, and can make the retail enterprise leading supply chain competitiveness significantly enhanced form. In strategic alliance, member enterprises should form fairness and trust relationship.

C. Establishment of efficient and quick information transmission network, strengthen the information exchange and sharing

In the retail enterprise leading supply chain, information obstacle problem will seriously hinder the overall function of the supply chain. To cope with such risks, we must establish efficient information transmission network. In addition, it is important to set up unified database in the retail enterprise leading supply chain information construction, and to establish efficient supply network system. In this way, through the establishment of a variety of information transmission channel, each enterprise in supply chain between can strengthen the exchange of information and communication, increase supply chain transparency and information sharing degree, and gradually eliminate information distortion or delay, beneficial to reduce between upstream and downstream firms do not trust, while reducing the retail enterprise leading supply chain information risk.

\section{Build a variety of supply channels for different supply}

There are a number of potential risks when goods are transported from the supplier to the retailers. Therefore, in order to maintain the retail enterprise leading supply chain flexibility, guarantee a steady supply of consumer goods, retail enterprises for some important consumer goods should be the development of a plurality of supply channels, not only relies on a supplier to complete, so that it can in a supplier problems also can guarantee the normal operation of business activities.

E. Strengthen the flexibility of supply chain to prevent the risk of supply chain

It is more flexible for retail enterprise leading supply chain to solve the bottleneck problem of supply chain. In order to meet consumer demand for products diversification and the personalized requirements needs, the retail enterprise leading supply chain upstream enterprises timely, quickly adjust their production supply cycle. This means that the retail supply chain design must pay attention to enterprise organization structure. On one hand, retail enterprises can be non core business to other companies in the supply chain. Other member enterprises can also be weak links in the implementation of the third party logistics outsourcing. On the other hand, the node enterprises should also adjust its own organizational structure, to make the enterprise stronger adaptability in line with the overall supply chain objectives.

\section{FUNDING}

This paper sponsored by project "Comparison research on the wisdom city regional development in Yangtze River Delta region” (No. C6203-12-030-2012)

\section{REFERENCES}

[1] Huang YF. A note on EOQ model under cash discount and payment delay[J]. Information and Management Sciences, 2005.

[2]Qiu hao, Liang Liang, Yang Shu. Optimal Retailers Ordering Policy under Permissible Delay in Payments and Cash Discount[J]. Systems Engineering, 2006.

[3] Weng Xingang, Li Zuoju. Thought on Chinese retail logistics supply chain management, logistics and procurement networks, November 2007

[4]Ma Lin. The global trade environment of supply chain risk management, economic science press, 2007

[5] Mu-Lin Ying, Zhang Jing. The supply chain management application in chain retail studies, of the collective economy in China, issue 2009 